\title{
Effectiveness of Mobile Applications in Vocabulary Teaching
}

\author{
Ahmet Basal, Selahattin Yilmaz, Asli Tanriverdi, \& Lutfiye Sari \\ Yildiz Technical University, Turkey
}

\begin{abstract}
Smartphones are increasingly becoming an ordinary part of our daily lives. With their remarkable capacity, applications used in these devices are extremely varied. In terms of language teaching, the use of these applications has opened new windows of opportunity, innovatively shaping the way instructors teach and students learn. This 4 week-long study aimed to investigate the effectiveness of a mobile application on teaching 40 figurative idioms from the Michigan Corpus of Academic Spoken English (MICASE) corpus compared to traditional activities. Quasi-experimental research design with pretest and posttest was employed to determine the differences between the scores of the control $(n=25)$ and the experimental group $(n=25)$ formed with convenience sampling. Results indicate that participants in the experimental group performed significantly better in the posttest, demonstrating the effectiveness of the mobile application used in this study on learning idioms. The study also provides recommendations towards the use of mobile applications in teaching vocabulary.
\end{abstract}

Keywords: English language teaching; Figurative idioms; Mobile learning; Mobile applications; Vocabulary teaching,

\section{Introduction}

Emerging technologies have brought about major changes in the teaching and learning processes (Pavlik, 2015). Mobile phones, one of these technologies, have led to a proliferation of studies that explore their use in education. Language teaching studies and practices have also been affected from this tide of change, as well (Stockwell, 2010). By providing flexible, practical, and personalized opportunities of use in and outside the classroom, mobile learning challenges the conventional ways of teaching remarkably (Kukulska-Hulme \& Traxler, 2005). Especially with smartphones that come with both powerful hardware and software, which makes them as capable as a computer, learning on the go becomes more and more convenient. As Stockwell (2015) highlighted, the big and touch-sensitive screen of today's smartphones offer great advantages in contrast to pre-smartphone mobile devices used in several studies (Hayati et al., 2013; Lu, 2008; Kukulska-Hulme,2010; Thornton \& Houser, 2005).

Vocabulary teaching is at the heart of developing proficiency and achieving competence in the target language. There has been constant effort in search of the best technique to teach vocabulary. In this context, although vocabulary is a core of foreign language learning, idiomatic expressions are the most frequently used non-literal expressions, and building blocks of daily conversations in a language, so lack of ability to use them competently can cause communication problems for the language learner such as sounding unnatural and inauthentic (Cooper, 1998, 1999). These expressions are particularly important to become proficient in the target language (Boers et al, 2006). Moreover, good command of idiomatic 
expressions is generally considered as becoming closer to the fluency of native speakers of the target language (Fernando, 1996; Schmitt, 2000; Wray, 2000). Therefore, as Irujo (1986) emphasized, teaching idioms should be an integral part of language teaching programs from beginning levels and taught in naturalistic contexts with ample chances of practice. However, while teaching idioms, difficulties arise (Zhang, 2009).

Mobile devices could open new doors with their unique qualities such as "accessibility, personalizability, and portability" (Saran \& Seferoglu, 2010, p.253), and "the physical characteristics (e.g., size and weight), input capabilities (e.g., keypad or touchpad), output capabilities (e.g., screen size and audio functions), file storage and retrieval, processor speed, and the [low] error rates" (Alzu'bi \& Sabha, 2013, p.179) in the teaching and learning processes.

\section{Literature Review}

The past decade has seen the rapid development in using mobiles phones in vocabulary teaching and the focus has been on the role of these devices in teaching vocabulary to L2 learners. A feature of mobile phones that was initially widely used in the studies was the SMS

(Short Message Service). Several experimental studies compared SMS-based vocabulary instruction to different types of more traditional instruction. For example, Lu (2008) and Zhang et al. (2011) both attempted to investigate the effect of SMS messages compared to printed materials. Results of their studies showed that SMS groups outperformed the control groups who were given printed materials in the posttest; however, there was no significant difference in the delayed posttests.

Similarly, Suwantarathip and Orawiwatnakul (2015) conducted an experimental study that compared the effect of in-class paper-based vocabulary exercises with SMS messages sent to students outside the classroom to teach and practice new vocabulary for a 6-week long period. The study reported that the participants in the experimental group outperformed the control group.

In addition to the text messaging capabilities of SMS, Saran and Seferoglu (2010) also used MMS (Multimedia Messaging Service) in their study. While the experimental group was taught vocabulary via SMS and MMS messages that included multimedia such as images and sounds, the control group was taught the same vocabulary items in the classroom. The scores of the experimental group were significantly higher than the control group in the post test.

In their study, to compare the effects of SMS versus paperback dictionaries in academic vocabulary learning, Alemi et al. (2012) found that there was no significant difference between vocabulary knowledge of two groups in the post tests; however, the SMS group was more successful in the delayed posttest. Furthermore, all these studies reported positive attitudes of students towards the use of SMS in vocabulary learning.

Platforms and programs other than messaging services were also used in teaching vocabulary on mobile devices. Thornton and Houser (2005) wanted to test the effectiveness of e-mails on mobile phones on vocabulary teaching. In the first 4 week-long experiment, they sent students mini vocabulary lessons via emails, which students received on mobile phones for the first 2 weeks, and via computers for the last 2 weeks. In the second experiment, students were divided into 2 groups, one of which received emails while the other had the same content as 
printed material. Students reported that using mobile phones was a more effective method and more preferable to computers and printed materials. The last experiment was the evaluation of a website that the authors, together with their students, developed to teach idioms. Vidioms included idioms with explanations, and examples through multimedia (sounds, images, videos). The authors asked a group of students to evaluate the website as they used it on mobile devices such as phones and PDAs. Students found the website significantly 'effective and enjoyable' (p. 225) to use on mobile devices.

Basoglu and Akdemir (2010) conducted a study on vocabulary learning to see the difference of use of mobile phones and flashcards. They used a mobile application for experimental group giving the words for six weeks while the control group learned the same words with flashcards. Their study reported a significant difference between two groups as the experimental group did achieve significantly better in the multiple-choice posttest.

Another example is Stockwell (2010) who compared vocabulary learning on mobile phones and computers in relation to student achievement, task completion speed, and time for a 3year period between 2007 and 2009. A Moodle-based system called VocabTutor was developed to run both on computers and mobile devices. Findings of the study showed no significant difference in terms of student scores; however, most students preferred using the system on computers with an increase of mobile phone use in 2009.

As a recent study that made use of smartphones, Wu (2015) created a mobile application called Word Learning-CET6 to teach vocabulary to a group of 70 Chinese college students. While the experimental group used the application, the control group was only reminded to study the vocabulary items on their own via text messages. The posttest results at the end of the experiment reported a significant different between two groups with experimental group outperforming the control group.

As can be seen in the above mentioned studies, experiments with different types of mobile learning tools varying from SMSs to applications that were written to teach vocabulary have all been proved to have benefits for the learners compared to more conventional ways of learning.

To the best knowledge of the researchers, few studies on idiom teaching through mobile devices were found in the literature. One of them is an experiment in Thornton and Houser (2005) which was the evaluation of a website that the authors, together with their students, developed to teach idioms. Vidioms included idioms with explanations, and examples through multimedia (sounds, images, and videos). The authors asked a group of students to evaluate the website as they used it on mobile devices such as phones and PDAs. Students found the website significantly 'effective and enjoyable' (p. 225) to use on mobile devices. Another study is by Hayati et al. (2013) who investigated the teaching of idioms to a group of 80 Iranian English learners. Students were divided into 3 groups, each of which received a different type of instruction to learn 80 idioms. The first group was the self-study group that received the idioms with their definitions and examples through printed material. The second group received 4 SMS messages that covered 4 idioms along with meanings and example sentences, while the last group was taught through short texts rather than definitions for a more contextualized instruction, and in the classroom. The post-test results showed that scores in all groups were significantly different, with SMS group being the highest, and the self-study group the lowest. Furthermore, responses to the post-experiment survey indicated that students mostly found use of mobile phones and SMS messages effective and preferable as a teaching 
method. As can be seen, both studies attempted to use mobile devices, however, neither of them was able to fully utilize what smartphones offers today with various free and easy-to-use applications that learners can easily reach.

Although many studies found SMS messages and other computer software adapted to mobile phone effective in vocabulary learning, affordances of these tools are limited. For example, SMS messages can be costly for students (Cavus \& Ibrahim, 2009) or computer programs require adjusting for mobile devices, which can cause problems in quality of use (Thornton \& Houser, 2005). Therefore, using the smartphone applications that are already well-functioning and popular among users could facilitate the mobile learning practices considerably. Moreover, applications of mobile learning are advantageous in language teaching (GodwinJones, 2011).

Wang and Shih (2015), for instance, used mobile vocabulary learning application in their study and concluded that experimental group scored significantly better than the control group who used paper-based learning materials. A good example of mobile applications is WhatsApp, a free mobile messenger application that allows its users to exchange texts, as well as multimedia both in one-to-one and group conversations, and make calls. Being one of the most popular and widely used messenger applications, it is also available for all mobile platforms (IOS, Android, Windows Mobile, Symbian, etc.).

As an effective means of mobile communication, WhatsApp has been used in some studies that aimed to investigate its effectiveness in terms of language learning. Plana et al. (2013) aimed to provide EAP students with extra reading activities by sending links to short texts and related comprehension questions through WhatsApp groups, as an alternative to SMS which is more costly, and less convenient without a computer system to send messages. The questionnaires after the twelve week-long implementation showed that students liked the activities, and increased their reading practice with the application.

Al Saleem (2014) aimed to examine the effect of dialogue journaling via WhatsApp on undergraduate English students' writing performance in terms of vocabulary and voice. During the six weeks of data collection, students were given 30 prompts to write on and via WhatsApp. The two writing tasks given as pre-test and post-test indicated that there was a significant improvement in students' writing in terms of their word choices and voice.

Lawrence (2014) also used WhatsApp groups in order to introduce vocabulary items before reading texts to a group of five undergraduate learners of Afrikaans. For a 7 week-long period, the researchers sent messages to the group that introduced target words with translations and different types of media such as sound or image. Content of the messages were further elaborated in each following course and students' knowledge was tested. The author concluded that WhatsApp is an effective tool for providing outside-the-classroom opportunities to practice vocabulary especially for weak students; however, content of the messages should be carefully planned.

Castrillo et al. (2014) investigated the role of WhatsApp in fostering negotiation of meaning among 85 Spanish learners of German. Based on the results of the pre-questionnaire, students were divided into 5 WhatsApp groups of five, where they discussed topics that the author sent. Students' interactions in terms of their negotiation of meaning and engagement with the tasks were analyzed. Students were found to have high levels of motivation and participation, as well as having improved their meaning negotiation skills. Although some research has been 
carried out on the use WhatsApp in vocabulary teaching and, there have been few empirical investigations into its use in idiom teaching. The present study therefore is set out to assess the effectiveness of the mobile application in teaching idioms.

\section{Research Design}

\section{Methodology}

This study aims to investigate the effectiveness of the mobile application on teaching 40 figurative idioms from the Michigan Corpus of Academic Spoken English (MICASE) compared to traditional activities. Posttest-only two-group randomized experimental design model was employed in the study. The research question that guided the study was: Are activities with the use of mobile applications more effective than traditional activities in increasing idiomatic knowledge of the participants?

\section{Participants}

The number of participants who took part in the study was 50 first-year students from an English Language Teaching Department of a state university in Turkey. Convenience sampling was employed while selecting the participants. Their level could be defined as upper intermediate since they are accepted to the department with Foreign Language Exam (YDS) scores. The participants were enrolled in the course called Lexical Competence in the spring semester of the academic year 2013-2014, a compulsory course aiming to expand the vocabulary knowledge of the students. The participants were divided into two groups randomly; control group consisted of 6 males and 19 females $(n=25)$ and experimental group $(n=25)$ consisted of 20 females and 5 and had an average of 20 in terms of their age. The control group was taught with traditional activities whereas the experimental group was taught with the use of mobile application.

\section{Data Analysis}

The idioms in this study were from Michigan Corpus of Academic Spoken English (MICASE). The corpus included contemporary speech recordings of 152 academic lectures over 197 hours from the University of Michigan between 1997 and 2001 (Simpson \& Mendis, 2003). Forty figurative idioms (e.g. ivory tower, bottom line, go off on a tangent, on the same page, litmus test, play devil's advocate, ring a bell, split hairs etc.) listed by Grant (2007) based on the study of Simpson and Mendis (2003) were used in the study.

The achievement test consisting of 40 questions on figurative idioms was used as the data collection tool. Internal validity of the questions in the test was established by using a panel of experts from the field of English language teaching. Each question answered correctly in the test was given 1 point. The test was used both as the pretest and posttest. The t-test was used to determine whether the differences between inter and intra groups were statistically significant. The achievement test included 40 fill-in-the blanks questions testing the knowledge of participants on figurative idioms. Sample items from the test are as follows: 
Please fill the blanks with the appropriate idioms from the list below. If necessary, please make changes.

the big picture /go off at a tangent / ivory tower / litmus test / put the heat on

1. Environmental groups are putting the heat on the government to stop pollution from power stations.

2. What does the professor know about student life, living as he does in an ivory tower?

3. The president's policy on abortion is regarded as a litmus test of his views on women's rights.

4. The ideal candidate for the job should be able to look at the big picture and prioritize work. Our discussion on fund-raising went off at a tangent, and we spent half the morning talking about political correctness.

\section{Procedures}

At the start of the study, the participants of the two groups were tested on their knowledge of the selected 40 figurative idioms. Based on this pretest results, there were no significant difference between the two groups, indicating that their knowledge level was similar on the selected idioms. The following week, the study and its focus on idioms were introduced to both groups. However, it is also important to consider the technology usage of the learners, and create the learning environments accordingly (Liu \& Milrad, 2010). As an indication of how quickly Turkish users have adopted mobile devices in recent years, Connected Customer Survey by Google (2014) indicated that smartphone usage reached 39\% and had tripled since 2012. Considering all these, teaching idioms through smartphones may be an effective way of integrating teaching into real life contexts.

In this context, the participants of the experimental group were asked whether they have WhatsApp mobile application on their mobile phones and how frequently they use them. All of the participants had this application on their mobile phones and stated that they used it frequently. After this check, the control group was given printed handouts including traditional activities on the idioms such the meaning of idioms, usage examples and fill in the blanks exercises. The experimental group on the other hand was taken MMS messages through the use of WhatsApp mobile application on a weekly basis.

Every week, $10 \mathrm{MMS}$ messages related with the target idioms (see appendix for the examples of MMS messages) were sent to the experimental group. The MMS contains the idiom, meaning of the idiom, a picture demonstrating the meaning of the idiom, and at least 3 sample sentences for each idiom. After sending MMS messages of 10 idioms, a mini test including fill in the blanks questions were sent to the participants as an MMS and the answers to the mini test was sent after 2 hours. This process took four weeks to complete. After the treatment completed, the achievement test was used as the posttest.

\section{Results}

The pretest results of the control group who learned idioms with traditional paper-based activities in the classroom can be seen in Table 1. Findings revealed that the participants in the 
control group achieved significant improvement $(p<000.5)$ on their idiom knowledge when the results of pretest $(M=15,24)$ and immediate posttest $(M=23,00)$ were compared. This means that after four weeks following the start of the study, participants in the control group experienced significant idiom-knowledge gains, suggesting that traditional activities were effective in teaching target idioms in the study.

Table 1. Paired Samples t-test Results Within Group

\begin{tabular}{lcccccc}
\hline & & & & \multicolumn{3}{c}{$t$-test } \\
\cline { 5 - 7 } & $\mathrm{N}$ & $\bar{x}$ & SD & $t$ & $d f$ & $p$ \\
\hline C. G. Pretest & 25 & 15,2400 & 5,54737 & \multirow{2}{*}{$-3,980$} & 24 & \multirow{2}{*}{001} \\
C. G. Posttest 1 & 25 & 23,0000 & 7,04746 & & & \\
\hline
\end{tabular}

The results of the pretest of the experimental group who learned idioms with the mobile application out of the classroom hours can be seen in Table 2. Findings revealed that the participants in the experimental group achieved significant improvement $(p<000.5)$ on their idiom knowledge when the results of pretest $(M=17,48)$ and posttest $(M=31,55)$ were compared. This means that after four weeks following the end of the treatment, participants in the experimental group also experienced significant idiom-knowledge gains, indicating that the use of mobile application was effective in teaching the target idioms in the study.

Table 2. Paired Samples t-test Results Within Group

\begin{tabular}{lcccccc}
\hline & & & & \multicolumn{3}{c}{ t-test } \\
\cline { 5 - 7 } & $\mathrm{N}$ & $\bar{x}$ & SD & $t$ & $d f$ & $p$ \\
\hline E. G. Pretest & 29 & 17,4828 & 9,40600 & & , \\
E. G. Posttest 1 & 29 & 31,5517 & 4,96118 & $-7,713$ & 28 & \\
\hline
\end{tabular}

The study aims to determine whether the use of mobile application was more effective than the traditional activities in teaching the target idioms. It is clear from Table 3 that both groups had significant idiom-knowledge gains after the 4-weeks-long study, demonstrating that the students in both groups improved their idiom-knowledge significantly independent of the group they were in and the activities they were supposed to do. However, as seen in the table, the experimental group achieved significantly better results on the posttest than the control group. In other words, when compared to the control group, idiom-knowledge gains of the experimental group were significantly higher than those of the control group, suggesting that the treatment was successful in teaching idioms.

Table 3. Independent Samples t-test Results Between Groups

\begin{tabular}{|c|c|c|c|c|c|c|}
\hline & \multirow[b]{2}{*}{$\mathrm{N}$} & \multirow[b]{2}{*}{$\bar{x}$} & \multirow[b]{2}{*}{ SD } & \multicolumn{3}{|c|}{$t$-test } \\
\hline & & & & $t$ & $d f$ & $p$ \\
\hline C. G. Pretest & 25 & 15,2400 & 5,54737 & $-1,045$ & 52 & 284 \\
\hline E. G. Pretest & 29 & 17,4828 & 9,40600 & & & \\
\hline C. G. Posttest 1 & 25 & 23,0000 & 7,04746 & $-5,210$ & 52 & ,001 \\
\hline E. G. Posttest 1 & 29 & 31,5517 & 4,96118 & & & \\
\hline
\end{tabular}




\section{Discussion and Conclusion}

Vocabulary learning is one of the most important aspects of language teaching. Idioms, an essential part of vocabulary knowledge, and idiomatic knowledge can help learners to become proficient in the target language (Boers et al., 2006). However, learning idioms is a major difficulty for many language learners in achieving a more natural sounding target language competence (Cooper, 1998, 1999). When it comes to teaching idioms, it becomes more difficult since it is hard to predict their meaning with the first look (Zhang, 2009). Therefore, there is a door of opportunities for creating appropriate environments to teach idioms, particularly with the use of broadly available technologies, one of which is through mobile applications.

Many studies proved that SMS messages and other computer programs adjusted to be used in mobile phones can be effective for vocabulary teaching. However, there may be some disadvantages of using SMS due to its cost (Cavus \& Ibrahim, 2009) and other computer programs due to the adjustment problems of these programs to mobile devices, causing low quality (Thornton \& Houser, 2005). Therefore, using the smartphone applications that are already well-functioning and popular among users could facilitate the mobile learning practices considerably. A good example of these applications is WhatsApp, a free mobile messenger application that allows its users to exchange texts, as well as multimedia both in one-to-one and group conversations, and make calls. Being one of the most popular and widely used messenger applications, it is also available for all mobile platforms (IOS, Android, Windows Mobile, Symbian etc.). This study aims to investigate the use the effectiveness of this mobile application on teaching 40 figurative idioms from the MICASE corpus compared to traditional activities.

Results of this study indicate that both the participants in the control and the experimental group significantly improved their knowledge of the target idioms independent of the activity type used in their respective groups. However, based on the posttest results, participants in the experimental group who learned idioms through the use of the mobile application achieved significantly better than their counterparts in the control group with traditional activities, indicating that use of the mobile application was more effective in teaching idioms than the traditional activities.

These results are in line with the results of several other studies employed SMS or MMS in the experimental group and traditional activities in the control group in vocabulary teaching (Lu, 2008; Saran \& Seferoglu, 2010; Zhang, 2011); however, they are contradictory with the findings of Alemi et al. (2012). On the other hand, even though Alemi did not find significant differences between the experimental and control groups on the posttest, the researcher found significant differences in the delayed posttest, indicating that using mobile applications significantly improved the retention of the vocabulary when compared to traditional activities. Moreover, the studies reported positive attitudes of students towards the use of mobile applications in teaching vocabulary.

In a study conducted by Hayati et al (2013) to teach idioms with three different ways (selfstudy, SMS, and more contextualized instruction in class), the results indicated that SMS group improved significantly better than the other two groups with positive feedback on using mobile phones and SMS in learning idioms. Basoglu and Akdemir (2010) also found that teaching vocabulary with mobile phones is more effective than presenting the vocabulary in flashcards. Lu (2008) also found that the participants of the SMS group recognized more 
vocabulary than the group learned vocabulary with printed materials. Suwantarathip and Orawiwatnakul (2015) also found that the experimental group in which mobile-assisted vocabulary exercises were used outperformed the control group receiving paper-based exercises. All the results of aforementioned four studies seem to be consistent with the results of the current research which found that using mobile applications is more effective in teaching vocabulary compared to the traditional ways of teaching.

Learning vocabulary in the classroom may be disadvantageous due to time constraints and the heavy responsibility on the learner (Grace, 1998). The advantage of using mobile phones and mobile applications in teaching vocabulary is having an opportunity to learn beyond classroom borders. In other words, "instructional activities are not limited to a set place... but can be conducted anywhere and anytime [and] learners can engage, often asynchronously, with teachers, learning resources and other learners" (Bornman, 2012, p.288).

However, as Kukulska-Hulme (2009) stated this can also be disadvantageous since the learning outside the classroom is beyond the control of the teacher, thus careful planning should be made to establish a strong connection between "what is best learnt in the classroom, [and] what should be learnt outside [the classroom]" (p.164). Therefore, teachers should have the responsibility of designing activities to achieve optimum balance between the content in- and outside the classroom. While maintaining such a balance, they should "seek ways to construct the content more enjoyable for their students" (Basal, 2012, p.167). In this process, with the use of mobile phones, learning activities may become more engaging (Cui \& Bull, 2005).

The current study contributed to the literature in that using mobile applications in vocabulary teaching can be a more effective tool when compared to traditional paper-based activities. However, designing language learning activities, in this case vocabulary learning activities, is a demanding task and requires careful planning. Moreover, while using mobile applications which are not tailored for vocabulary teaching, language teachers should be aware of pedagogical considerations in the design of the vocabulary activities. Language teachers should also pay special attention to the use of ready-made mobile applications for vocabulary teaching since the number of them are countless and although they were originally tailored for vocabulary teaching and the developers of them claim that they were carefully designed in line with the scientific findings related to vocabulary teaching, to prove these claims can be a daunting task to their huge numbers. Therefore, teachers should know how to evaluate the usefulness of these applications for vocabulary teaching.

This study has some limitations regarding the limited number of the participants. Large-scale studies need to be done in order to understand its strengths and weaknesses in teaching specific aspects of language. Moreover, more research needs to be undertaken in order to confirm the strength of the association between mobile applications and their effectiveness in teaching vocabulary.

\section{References}

Alemi, M., Sarab, M. R. A., \& Lari, Z. (2012). Successful learning of academic word list via MALL: Mobile assisted language learning. International Education Studies, 5(6),99-109 . http://dx.doi.org/10.5539/ies.v5n6p99 
Alsaleem, B. I. A. (2013). The effect of "WhatsApp" electronic dialogue journaling on improving writing vocabulary word choice and voice of EFL undergraduate Saudi students. Arab World English Journal, 4(3), 213-225.

Alzu'bi M.A.M. \& Sabha, M. R. N. (2013). Using mobile-based email for English foreign language learners. Turkish Online Journal of Educational Technology-TOJET, 12(1), 178186.

Basal, A. (2012). Authorıng tools for developing the content in language education. International Journal on New Trends in Education \& Their Implications (IJONTE), 3(4), 164-169.

Basoglu, E. B. \& Akdemir, O. (2010). A comparison of undergraduate students' English vocabulary learning: Using mobile phones and flash cards. Turkish Online Journal of Educational Technology-TOJET, 9(3), 1-7.

Boers, F., Eyckmans, J., Kappel, J., Stengers, H., \& Demecheleer, M. (2006). Formulaic sequences and perceived oral proficiency: Putting a lexical approach to the test. Language Teaching Research, 10(3), 245-261.

Bornman, E. (2012). The mobile phone in Africa: has it become a highway to the information society or not? Contemporary Educational Technology, 3(4), 278-292.

Castrillo, M. D., Martín-Monje, E., \& Bárcena, E. (2014). Mobile-based chatting for meaning negotiation in foreign language learning. In Proceedings of the 10th International Conference on Mobile Learning. International Association for Development of the Information Society (pp. 49-59).

Cooper, T. C. (1998). Teaching idioms. Foreign Language Annals, 31(2), 255-266. http://dx.doi.org/10.1111/j.1944-9720.1998.tb00572.x

Cooper, T. C. (1999). Processing of idioms by L2 learners of English. Tesol Quarterly, 33(2), 233262. http://dx.doi.org/10.2307/3587719

Cui, Y. \& Bull, S. (2005). Context and learner modeling for the mobile foreign language learner. SYSTEM, 33(2), 353-367. http://dx.doi.org/10.1016/j.system.2004.12.008

Fernando, C. (1996). Idioms and idiomaticity. Oxford: Oxford University Press.

Godwin-Jones, R. (2011). Mobile apps for language learning. Language Learning \& Technology, 15(2), 2-11.

Grace, C. A. (1998). Retention of Word Meanings Inferred from Context and Sentence-Level Translations: Implications for the Design of Beginning-Level CALL Software. The Modern Language Journal, 82(4), 533-544. http://dx.doi.org/10.1111/j.15404781.1998. tb05541.x

Grant, L. E. (2007). In a manner of speaking: Assessing frequent spoken figurative idioms to assist ESL/EFL teachers. System, 35(2), 169-181.

Hayati, A., Jalilifar, A., \& Mashhadi, A. (2013). Using Short Message Service (SMS) to teach English idioms to EFL students. British Journal of Educational Technology, 44(1), 66-81. http://dx.doi.org/10.1111/j.1467-8535.2011.01260.x

Irujo, S. (1986). A piece of cake:/earning and teaching idioms. ELT journal, 40(3), 236-242. http://dx.doi.org/10.1093/elt/40.3.236 
Kukulska-Hulme, A. (2009). Will mobile learning change language learning?. ReCALL, 21(02), 157-165. http://dx.doi.org/10.1017/S0958344009000202

Kukulska-Hulme, A. (2010). Learning Cultures on the Move: Where are we heading?. Journal of Educational Technology and Society, 13(4), 4-14.

Kukulska-Hulme, A., \& Traxler, J. (Eds.). (2005). Mobile learning: A handbookfor educators and trainers. Psychology Press.

Lawrence, D. (2014) Students' Experiences of Using SMS for Vocabulary Development-a Case Study. In Conference proceedings of ICT for language learning (p. 310). Available at: http://www.libreriauniversitaria.

Liu, C. C. \& Milrad, M. (2010). Guest editorial-one-to-one learning in the mobile and ubiquitous computing age. Educational Technology \& Society, 13(4), 1-3.

Lu, M. (2008). Effectiveness of vocabulary learning via mobile phone. Journal of computer assisted learning, 24(6), 515-525.

Schmitt, N. (2000). Vocabulary in language teaching. Cambridge: Cambridge University Press.

Simpson, R. \& Mendis, D. (2003). A corpus-based study of idioms in academic speech. TESOL Quarterly, 37(3), 419-441. http://dx.doi.org/10.2307/3588398

Pavlik, J. V. (2015). Fueling a third paradigm of education: The pedagogical implications of digital, social and mobile media. Contemporary Educational Technology, 6(2), 113-125.

Plana, M. G. C., Escofet, M. I. G., Figueras, I. T., Gimeno, A., Appel, C., \& Hopkins, J. (2013). Improving learners' reading skills through instant short messages: A sample study using WhatsApp. Proceeding of WorldCall (pp.80-84). Glasgow, UK: University of Ulster.

Saran, M. \& Seferoglu, G. (2010). Supporting foreign language vocabulary learning through multimedia messages via mobile phones. Hacettepe University Journal of Education, 38, 252-266.

Stockwell, G. (2010). Using mobile phones for vocabulary activities: Examining the effect of the platform. Language Learning \& Technology, 14(2), 95-110.

Suwantarathip, O. \& Orawiwatnakul, W. (2015). Using mobile-assisted exercises to support students' vocabulary skill development. Turkish Online Journal of Educational Technology, 14(1), 163-171.

Thornton, P. \& Houser, C. (2005). Using mobile phones in English education in Japan. Journal of computer assisted learning, 21(3), 217-228. http://dx.doi.org/10.1111/j.13652729.2005.00129.x

Wang, Y. H. \& Shih, S. K. H. (2015). Mobile-assisted language learning: Effects on EFL vocabulary learning. International Journal of Mobile Communications, 13(4), 358-375. http://dx.doi.org/10.1504/IJMC.2015.070060

Wray, A. (1999). Formulaic language in learners and native speakers. Language Teaching, 32, 213-231. http://dx.doi.org/10.1017/S0261444800014154

Zhang, L. (2009). The effect of etymological elaboration on L2 idiom acquisition and retention in an online environment (WebCT) (Unpublished doctoral dissertation). Retrieved on 15 June 2015 from Graduate College at Digital Repository @ lowa State University (Paper 11126). http://dx.doi.org/10.1504/IJMC.2015.070060 
CONTEMPORARY EDUCATIONAL TECHNOLOGY, 2016, 7(1), 47-59

Zhang, H., Song, W., \& Burston, J. (2011). Reexamining the Effectiveness of Vocabulary Learning via Mobile Phones. Turkish Online Journal of Educational Technology-TOJET, 10(3), 203-214.

Correspondence: Ahmet Basal, Assistant Professor, Department of Foreign Language Education, Faculty of Education, Yildiz Technical University, Davutpasa Campus, Esenler, Istanbul, Turkey 


\section{Appendix}

\section{Examples of WhatsApp Messages for the Experimental Group}

\section{the Gig/bigger picture}

The most important facts about a situation and the effects of that situation on other things.

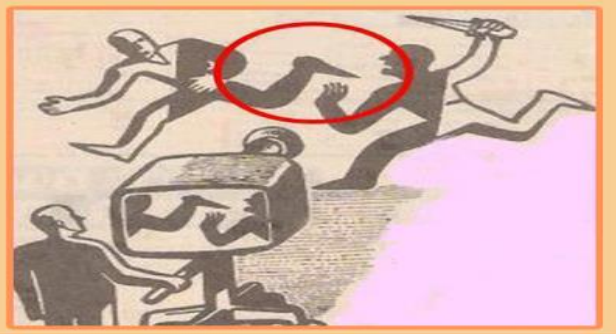

- If someone can't see the wood for the trees, they get so caught up in small details that they fail to understand the bigger picture.

- In my political work I try to concentrate on the big picture and not be distracted by details.

- Ile's so involved in the minutiae that he often overlooks the Gig picture

\section{ivory tower}

To live or Ge in an ivory tower is not to know about or to want to avoid the ordinary and unpleasant things that happen in people's lives.

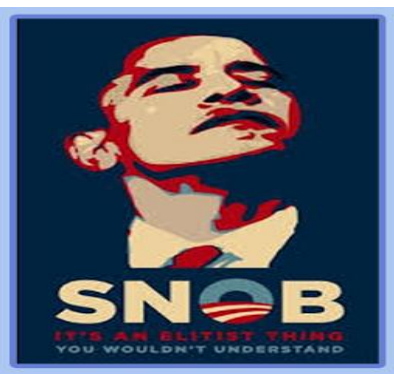

- You're completely out of touch - it's time to come out of your ivory tower and see what's going on!

- He needs to get out of his ivory tower and put his feet on the ground.

- Let those scholars criticize our Geliefs from their ivory tower; we all know how the world really works. 